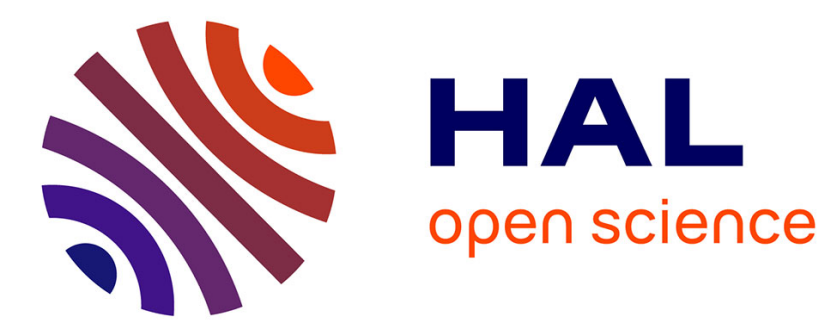

\title{
Thermodynamic analysis of the Stirling Duplex machine
}

Georges Heyihin, Christophe Awanto, Malahimi Anjorin, Aristide Hougan,

François Lanzetta

\section{To cite this version:}

Georges Heyihin, Christophe Awanto, Malahimi Anjorin, Aristide Hougan, François Lanzetta. Thermodynamic analysis of the Stirling Duplex machine. International Conference on Smart City and Communities, Jul 2018, Ouagadougou, Burkina Faso. hal-02370543

\section{HAL Id: hal-02370543 \\ https://hal.science/hal-02370543}

Submitted on 19 Nov 2019

HAL is a multi-disciplinary open access archive for the deposit and dissemination of scientific research documents, whether they are published or not. The documents may come from teaching and research institutions in France or abroad, or from public or private research centers.
L'archive ouverte pluridisciplinaire HAL, est destinée au dépôt et à la diffusion de documents scientifiques de niveau recherche, publiés ou non, émanant des établissements d'enseignement et de recherche français ou étrangers, des laboratoires publics ou privés. 


\section{Thermodynamic analysis of the Stirling Duplex machine}

\author{
$1^{\text {st }}$ Georges HEYIHIN \\ Energy and Applied Mechanics Laboratory \\ Universty of Abomey-Calavi \\ Abomey-Calavi, Benin Republic \\ gheyihin@gmail.com
}

\author{
$2^{\text {nd }}$ Christophe AWANTO \\ Energy and Applied Mechanics Laboratory \\ Universty of Abomey-Calav \\ Abomey-Calavi, Benin \\ christophe.awanto@gmail.com
}

\author{
$5^{\text {th }}$ Franois LANZETTA \\ FEMTO-ST
}

Energy and Applied Mechanics Laboratory Energy and Applied Mechanics Laboratory

Universty of Abomey-Calav

Universty of Abomey-Calav

Abomey-Calavi, Benin

hounaris@yahoo.fr

\begin{abstract}
The Stirling Duplex concept, in which a Stirling engine drives a Stirling heat pump, has many energy and environmental benefits. This machine is essentially composed of three movable elements, a working piston and two displacers, in the same enclosure. The machine has two circuits of nonpolluting working fluid, in both parts, engine and refrigerator. The compatibility of the Stirling machine with any type of thermal energy as an external combustion engine contributes to its industrial interests and scientific research. In this paper, a study is presented to estimate Stirling Duplex's parameters and efficiencies by considering the adiabatic model.
\end{abstract}

Index Terms-Stirling Duplex, adiabatic model, engine, cooler

\section{INTRODUCTION}

Ever-growing energy needs and the resulting environmental problems have intensified research into renewable energies and new cleaner engines. The operation of Stirling machines is in line with the efficient use of energy and the protection of the environment, and as a result they have become the main focus of recent scientific and industrial research. Numerous scientific institutes or commercial companies have invested to contribute to the development of Stirling machines [1]-[5]. The Stirling engine was invented by Robert Stirling in September 1876, and was used to train wagons in coal mines. Due to the lack of materials and the high cost above those of others machines, the Stirling engine has not had much industrial success. But the scarcity of fossil fuels and the use of renewable energies have led to renewed research around Stirling machines. The Stirling engine is a high efficiency, simple, quiet and highly reliable tool that is non-polluting and requires little maintenance [6]. Its compatibility with any type of thermal energy as an external combustion engine contributes to its scientific and industrial interests. The reversibility of the Stirling cycle is used for cold generation. Driven by a motor, the machine becomes a refrigerating machine or a heat pump. The Duplex machine used as a heat pump or refrigerator is essentially two freepiston Stirling machines sharing a common piston and an under pressure enclosure. When the high temperature heat is supplied to the heater, the "motor" part produces mechanical energy that is used by the heat pump to extract heat from the cold source to the hot well [7].

The domestic refrigeration and air-conditioning market is currently dominated by refrigerant compression machines containing chlorofluorocarbons (CFCs) which destroy the ozone layer. In fact, CFCs released into the atmosphere have an important power of chemical transformations of the ozone layer, protecting the earth against ultraviolet rays. The Stirling refrigerator would therefore be an environmental solution against the use of chlorinated refrigerant compression machines. The use of Stirling Duplex will solve two problems of the century simultaneously:

- Energy solution: the use of renewable energies such as solar energy, biomass, etc., as thermal energy at the input of the engine, to the detriment of fossil energies;

- Protection of the environment: the reduction of refrigerants destroying the ozone layer. In this document, the performances of the Stirling Duplex for refrigeration production are estimated.

\section{DESCRIPTION OF THE STIRLING DUPLEX MACHINE}

\section{A. Presentation of the Stirling Duplex machine}

The Stirling Duplex machine is the type of combined cycle machine where Stirling cycle engine drives the reverse Stirling cycle. This device used as a refrigeration tool is essentially composed of two free-piston Stirling machines arranged (backto-back), linked together by a common piston in a same enclosure. A set of displacer and piston operating in motor, drives another set, which in turn works as a heat extractor. In both parts, the displacer is driven by the pressure differential between the compression and expansion spaces on either side of the displacer. Each section of the Stirling Duplex (engine or cooler) contains all the main elements of a Stirling machine 
such as the heater, the regenerator, the cooler, the displacer and the piston [7]. The uniqueness of the design comes from the fact that the two Stirling machines have the same piston, resulting from the configuration of three moving components (Figure 1). When the high temperature heat is supplied to the heater, the "motor" portion generates mechanical energy that is used by the heat pump to extract heat from the cold source to the hot well. The system from these three components is a potentially efficient, simple and durable heat pump pump, with, of course, all the advantages associated with free-piston Stirling engines. The concept of the free-piston Stirling Duplex engine has its roots in the history of free-piston engines. Current Stirling machines such as refrigerators or heat pumps are built at SUNPOWER, and have been used all over the world since 1979 [7].

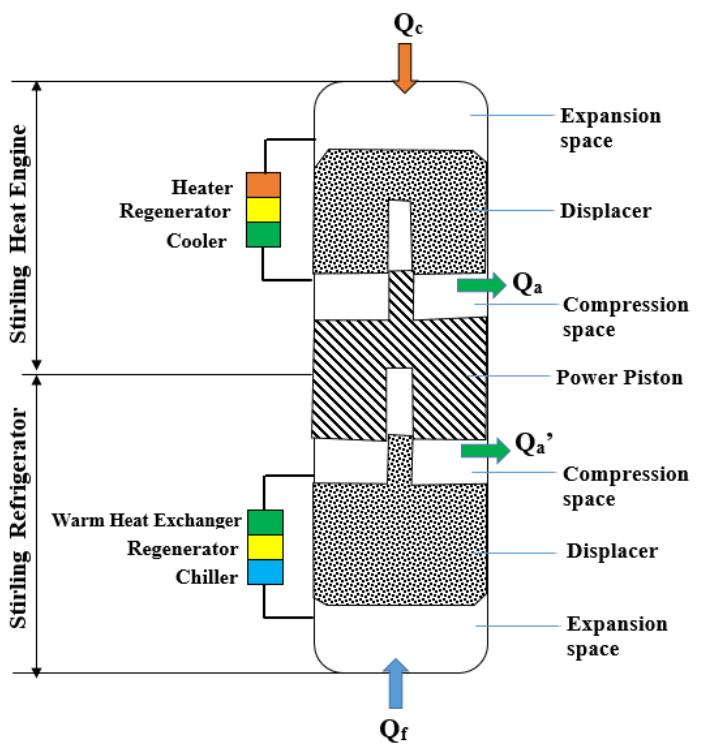

Fig. 1. Representation of the Stirling Duplex machine.

\section{B. Ideal Stirling Duplex cycle}

The ideal Stirling cycle is a reversible thermodynamic cycle with two isothermal transformations and two isochoric transformations. As the two parts of the Stirling Duplex work with separate working fluids, the cycle described by the Stirling Duplex machine is dual: the motor cycle and the cooler cycle (Figure 2) [8].

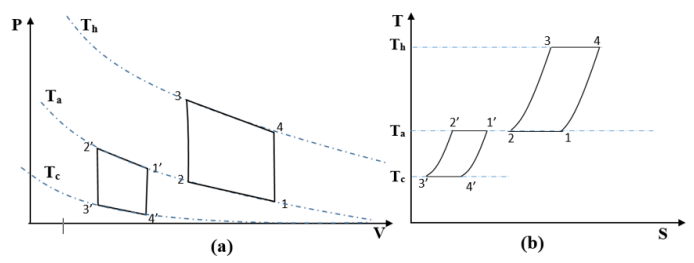

Fig. 2. : Operation Cycle of the Duplex machine
- Isothermal Compression (Engine: 1-2, Refrigerator: 1'$2^{\prime}$ ): During this process, the power piston moves, reducing the volume of the compression zone, while the displacer remains stationary. The working fluid is compressed in the compression zone and the pressure increases. The intermediate temperature $\left(T_{a}\right)$ is kept constant due to the exchange of heat through the heat exchanger (the hot well). At the refrigerator, work is received.

- Isochoric heating (Engine: 2-3, Refrigerator: 2'-3'): the two pistons move in the same direction, maintaining the constant inter-piston volume. The working fluid is transferred from the compression zone to the expansion zone through the regenerator. At the motor, the fluid temperature increases by heat absorption at the regenerator, also increasing the pressure. At the chiller, the fluid temperature decreases with heat loss

- Isothermal expansion (Engine: 3-4, Refrigerator: 3'-4 '): in this phase, the displacer continues to move while the piston remains stationary. Like any relaxation, the pressure of the fluid drops in front of the increase of the volume of the expansion chamber. The temperature remains constant by the external heat input which compensates the cooling. At the engine, work is provided and at the heat sink is absorbed from the medium to be cooled.

- Isochoric cooling: (Engine: 4-1, Refrigerator 4'-1 '). During this phase, the two pistons move simultaneously transferring the working fluid from the expansion space to that of compression through the regenerator, without volume variation. During this transfer of fluid, heat is transferred to the regenerator thereby reducing the temperature of the gas. At the chiller, the amount of heat is transferred from the regenerator to the fluid, thereby increasing its fluid temperature.

\section{THERMODYNAMIC EQUATIONS}

The adiabatic cycle assumes that the compression and expansion spaces are perfectly insulated. This is more realistic and adiabatic conditions can be safely assumed since the machines operate at high frequencies allowing little or no time for heat transfer in the working spaces. All heat input to the cycle occurs in the heater, and all heat output occurs in the cooler. Gases leave the heater at the heat source temperature and are mixed perfectly as soon as they enter the expansion space. Similarly, gases leave the cooler at the heat sink temperature and are mixed perfectly as soon as they enter the compression space. In this case too, perfect regeneration is assumed.

This section describes the adiabatic model proposed by Urielli [9] , where each of the two machines parts is represented in five compartments :

- Compression space $(c)$

- Cooler exchanger $(k)$

- Regenerator $(r)$

- Heater exchanger $(h)$ 
- Expansion space (e)

This study is based on the following assumptions:

- The expansion and compression processes are adiabatic

- The temperature of hot end heat exchanger, cold end heat exchanger and regenerator is constant.

- The working fluid obeys ideal gas law.

- The specific heats for the working fluid are constant.

- The pressure is uniform throughout each of two machines parts at all instants.

- Perfect regeneration occurs in the regenerator volume.

1) Pressure and volume variation: The evaluation of the pressure along the Stirling machine is calculated considering the mass balance applied to the overall machine.

$$
m=m_{c}+m_{k}+m_{r}+m_{h}+m_{e}
$$

The mass balance is re-written in a form that allows the calculation of the pressure.

$$
p=\frac{m \cdot r}{\frac{V_{c}}{T_{c}}+\frac{V_{k}}{T_{k}}+\frac{V_{r}}{T_{r}}+\frac{V_{h}}{T_{h}}+\frac{V_{e}}{T_{e}}}
$$

The Duplex machine is similar to a combination of two (2) beta-type Stirling machines associated "back-to-back"; the geometrical parameters of each section of the Duplex are those of the Stirling beta. The volumes of the compression and expansion chambers as a function of the harmonic movement of the piston are given by the following formulas [10]:

$$
\begin{gathered}
V_{c}=\frac{V_{s w e}}{2} \cdot(1-\cos (\varphi))+\frac{V_{s w c}}{2} \cdot(1-\cos (\varphi-\alpha)) \\
V_{e}=\frac{V_{s w e}}{2} \cdot(1-\cos (\varphi))
\end{gathered}
$$

2) Mass drivatives and mass flow: The derivatives of the mass $\mathrm{i}$ respect to the angle position of the power piston for each heat exchanger, which are assumed isothermal, are calculated from equation (5)

$$
\frac{d m_{i}}{d \varphi}=\frac{m_{i}}{p} \cdot \frac{\partial p}{\partial \varphi}, i=k, r, h
$$

The derivatives for the compression and expansion spaces, which are not isothermal, are evaluated by the equations below:

$$
\begin{aligned}
\frac{d m_{c}}{d \varphi} & =\frac{p \cdot\left(\frac{\partial V_{c}}{\partial \varphi}\right)+\frac{V_{c} \cdot\left(\frac{\partial p}{\partial \varphi}\right)}{\gamma}}{R \cdot T_{c k}} \\
\frac{d m_{e}}{d \varphi} & =\frac{p \cdot\left(\frac{\partial V_{e}}{\partial \varphi}\right)+\frac{V_{e} \cdot\left(\frac{\partial p}{\partial \varphi}\right)}{\gamma}}{R \cdot T_{h e}}
\end{aligned}
$$

The mass flows at the interfaces are evaluated with equations (8), (9), (10), (11) applied to each control volume:

- Between the compression space and the cooler:

$$
m_{c k}=-\frac{\partial m_{c}}{\partial \varphi}
$$

- Between the cooler and the regenerator:

$$
m_{k r}=m_{c k}-\frac{\partial m_{c}}{\partial \varphi}
$$

- Between the regenerator and the heater:

$$
m_{r h}=m_{h e}+\frac{\partial m_{h}}{\partial \varphi}
$$

- Between the expansion space and the heater:

$$
m_{h e}=\frac{\partial m_{e}}{\partial \varphi}
$$

3) Pressions variation: The analytical formula for change in pressure based on energy balance is given by:

$$
\frac{d p}{d \varphi}=-\frac{\gamma \cdot p \cdot\left(\frac{\left(\frac{\partial V_{c}}{\partial \varphi}\right)}{T_{c k}}+\frac{\left(\frac{\partial V_{e}}{\partial \varphi}\right)}{T_{h e}}\right)}{\frac{V_{c}}{T_{c k}}+\gamma \cdot\left(\frac{V_{k}}{T_{k}}+\frac{V_{r}}{T_{r}}+\frac{V_{h}}{T_{h}}\right)+\frac{V_{e}}{T_{h e}}}
$$

4) Temperature variation: The variation of the temperature inside the Stirling machine is assumed to follow the scheme shown below [11].

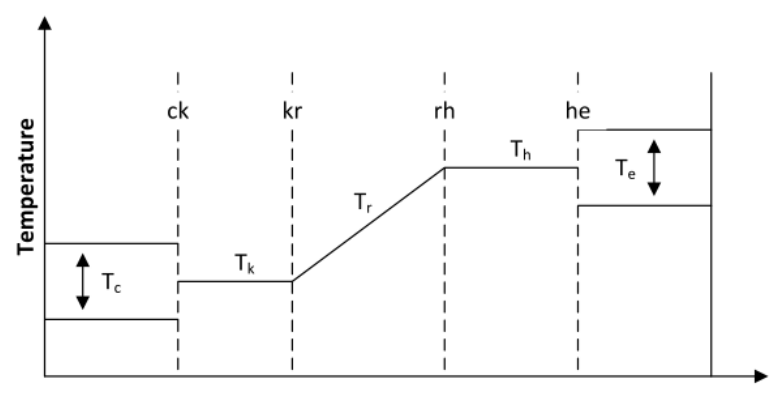

Fig. 3. : Temperature variation inside the control volumes

This scheme shows that the heater and cooler temperatures are assumed to be constant and the regenerator temperature is assumed to vary linearly. The linear variation permits the evaluation of a mean effective temperature for the regenerator space.

$$
T_{r}=\frac{T_{h}-T_{k}}{\ln \left(\frac{T_{h}}{T_{k}}\right)}
$$

The temperatures in the compression and expansion spaces change over the cycle. These are calculated with the differential form of the equation of state for the working gas.

$$
\begin{aligned}
& \frac{d T_{c}}{d \varphi}=T_{c} \cdot\left(\frac{\left(\frac{\partial p}{\partial \varphi}\right)}{p}+\frac{\left(\frac{\partial V_{c}}{\partial \varphi}\right)}{V_{c}}-\frac{\left(\frac{\partial m_{c}}{\partial \varphi}\right)}{m_{c}}\right) \\
& \frac{d T_{e}}{d \varphi}=T_{e} \cdot\left(\frac{\left(\frac{\partial p}{\partial \varphi}\right)}{p}+\frac{\left(\frac{\partial V_{e}}{\partial \varphi}\right)}{V_{e}}-\frac{\left(\frac{\partial m_{e}}{\partial \varphi}\right)}{m_{e}}\right)
\end{aligned}
$$

The boundary temperatures Tck and The change with the direction of the flow. Therefore the following conditional equations are used to calculate these temperatures.

$$
\text { If } m_{c k}>0 \text { then } T_{c k}=T_{c} \text { else } T_{c k}=T_{k}
$$




$$
\text { If } m_{h e}>0 \text { then } T_{h e}=T_{h} \text { else } T_{h e}=T_{e}
$$

The other pair of boundary temperatures ( $\mathrm{Tkr}$ and Trh), are assumed constant and equal to the cooler and heater temperatures respectively for the ideal adiabatic model these

$$
\begin{aligned}
& T_{k r}=T_{k} \\
& T_{r h}=T_{h}
\end{aligned}
$$

5) Energy balances : The energy balance applied to each heat exchanger, taking into account that these are isothermal spaces, gives the following expressions:

- Cooler:

$\frac{d Q_{k}}{d \varphi}=\frac{V_{k} \cdot\left(\frac{\partial p}{\partial \varphi}\right) \cdot C_{v}}{R}-C_{p} \cdot\left(T_{c k} \cdot m_{c k}-T_{k r} \cdot m_{k r}\right)$

- Regenerator:

$\frac{d Q_{r}}{d \varphi}=\frac{V_{r} \cdot\left(\frac{\partial p}{\partial \varphi}\right) \cdot C_{v}}{R}-C_{p} \cdot\left(T_{k r} \cdot m_{k r}-T_{r h} \cdot m_{r h}\right)$

- Heater:

$\frac{d Q_{h}}{d \varphi}=\frac{V_{h} \cdot\left(\frac{\partial p}{\partial \varphi}\right) \cdot C_{v}}{R}-C_{p} \cdot\left(T_{r h} \cdot m_{r h}-T_{h e} \cdot m_{h e}\right)$

The compression and expansion work are calculated from the energy balance applied to the corresponding working spaces, which are assumed adiabatic.

$$
\begin{aligned}
& \frac{d W_{c}}{d \varphi}=p \cdot\left(\frac{\partial V_{c}}{\partial \varphi}\right) \\
& \frac{d W_{e}}{d \varphi}=p \cdot\left(\frac{\partial V_{e}}{\partial \varphi}\right)
\end{aligned}
$$

The work output of the Stirling engine or refrigerator is the sum of the compression and expansion work on the machine.

$$
W=W_{c}+W_{e}
$$

The mechanical powers absorbed in the engine section, and transmitted in the chiller section by the power piston are given by and [7]: These powers are a function of the phase () of the movement of the displacer relative to to the movement of the power piston

$$
\begin{gathered}
P_{m}=p_{m} \cdot A \cdot X \cdot \pi \cdot f \cdot \sin \left(\varphi_{m}\right) \\
P_{f}=p_{f} \cdot A \cdot X \cdot \pi \cdot f \cdot \sin \left(\varphi_{f}\right)
\end{gathered}
$$

Like all combined cycle machines, the work indicated at the output of the engine section is equal to that of the heat pump [12].This makes it possible to write the following relationship between the average pressures in the Stirling engine and the Stirling cooler:

$$
p_{f}=p_{m} \cdot \frac{\sin \left(\varphi_{m}\right)}{\sin \left(\varphi_{f}\right)}
$$

6) Coefficient of performance: Two performance factors can be considered for the Stirling Duplex machine: it is $C O P_{h}$ when it is used as a heat pump, and the $C O P_{f}$ as a refrigerating machine.

$$
\begin{gathered}
C O P_{h}=\frac{Q_{k m}+Q_{k f}}{Q_{h}} \\
C O P_{f}=\frac{Q_{f}}{Q_{h}}
\end{gathered}
$$

\section{SIMULATION RESULTS AND DISCUSSIONS}

In what follows, the numerical solution algorithm is presented, see Fig.4. The adiabatic Stirling Duplex model is analysed and simulated to evaluate its performance and operating parameters. The basic parameters and simulation conditions are presented in Table 1 . The geometric dimensions are those of a Stirling engine used by A. Asnaghy et al in their work in 2012 [13]

TABLE I

BASIC PARAMETERS OF THE STIRLING DUPLEX

\begin{tabular}{|c|c|}
\hline Parameters & Value \\
\hline Expansion sweep volume & $160 \mathrm{~cm}^{3}$ \\
\hline Compression sweep volume & $160 \mathrm{~cm}^{3}$ \\
\hline Hot piston dead volume & $30 \mathrm{~cm}^{3}$ \\
\hline Cold piston dead volume & $40 \mathrm{~cm}^{3}$ \\
\hline Regenerateur dead volume & $30 \mathrm{~cm}^{3}$ \\
\hline Heater temperature & $923 \mathrm{~K}$ \\
\hline Coller temperature & $300 \mathrm{~K}$ \\
\hline Chiller temperature & $263 \mathrm{~K}$ \\
\hline Phase angle difference & $\frac{\pi}{2} \mathrm{rad}$ \\
\hline Phase angle between displacers & $\frac{\pi}{4} \mathrm{rad}$ \\
\hline
\end{tabular}

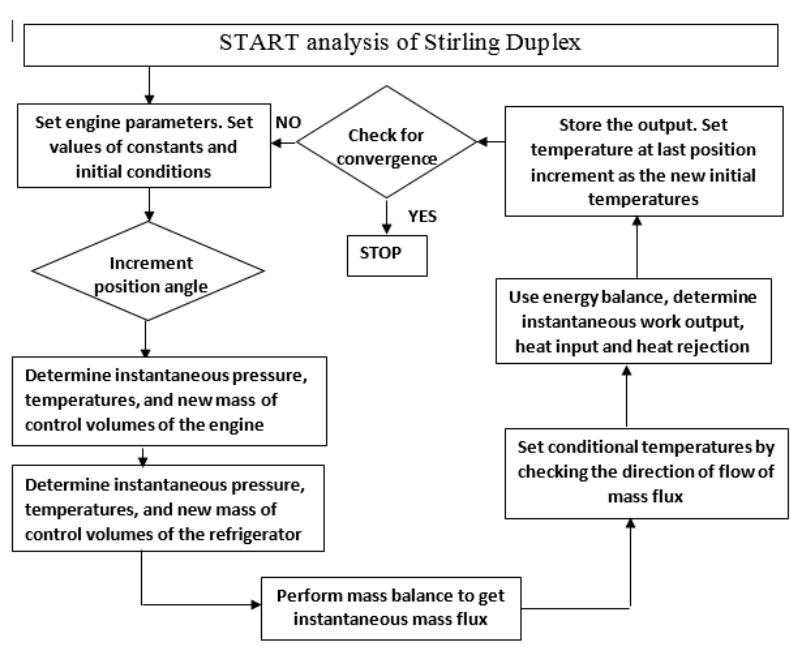

Fig. 4. Flowchart of the simulation

\section{A. Stirling Duplex Machine Parameters}

Fig.5 shows the Clapeyron P-V diagram of the Duplex machine. The two curves obtained make it possible to determine the net works supplied and received after a cycle of operation. 
These works, represented numerically by the curved areas in the P-V diagram, are called the indicated works of the machine. Table 2 shows the characteristics and performance of the Stirling machine for one operating cycle.

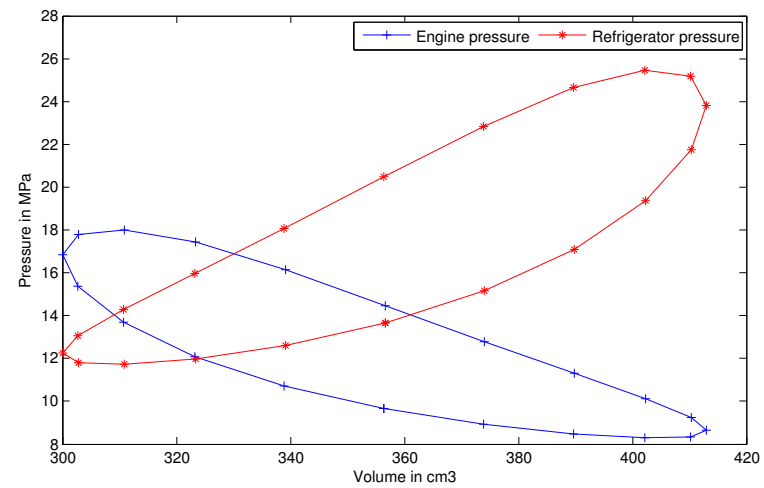

Fig. 5. Pression-Volume diagram of the Duplex

TABLE II

CHARACTERISTICS AND PERFORMANCES OF THE MACHINE

\begin{tabular}{|c|c|}
\hline Parameters & Value \\
\hline Working fluid & Helium \\
\hline Average pressure (MPa) & Engine : 12,0; Refrigerator: 18,0 \\
\hline Indicated work (J) & 499,5 \\
\hline Refrigerating enrgy (J) & 639,1 \\
\hline Heat supplied (J) & 1250 \\
\hline$C O P_{f}$ & 0.5 \\
\hline$C O P_{h}$ & 1.5 \\
\hline
\end{tabular}

1) Volume variation: Fig.6 and Fig.7 show the volume variations respectively the engine-Stirling and cooler-Stirling sections. The variation of the total volume of each Stirling section depends almost on the variation of the volume of the compression space. This is explained by the shape of the Duplex machine composed of two Stirling beta where the instantaneous volume of the compression space is the sum of the volumes "scanned" by the displacer on the one hand and by the power piston on the other hand share.

At the Fig. 8 illustrating the volumes in the compression and expansion spaces, the variations of the expnsion volumes while those of the compression volumes are out of phase by $\frac{\pi}{4}$ $\mathrm{rad}$; this is the phase's difference of the displacers with respect to the piston [7].

2) Pressure variation: Fig.9 shows the variation of the average pressures in the two sections of the machine. The pressures variation are similar in that they are linked by the periodic phase evolution of the gas in the two sections (28).

3) Thermal balance: The Stirling Duplex can be used as a refrigerating machine or a heat pump. Fig.10 shows the variations of heat quantities, supplied at the input of the machine, produced as a heat pump and extracted as a refrigerating machine. It appears that the Stirling Duplex is more efficient as a heat pump than as a refrigerating machine (Table II).

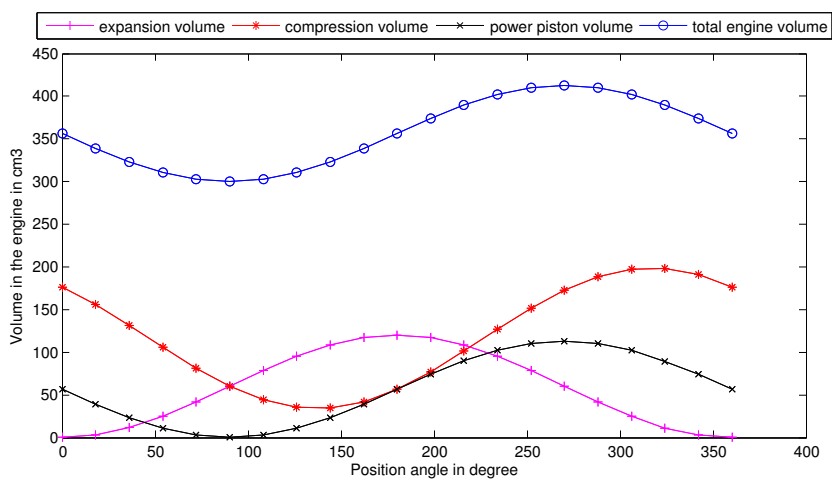

Fig. 6. Variation volume in the engine-section

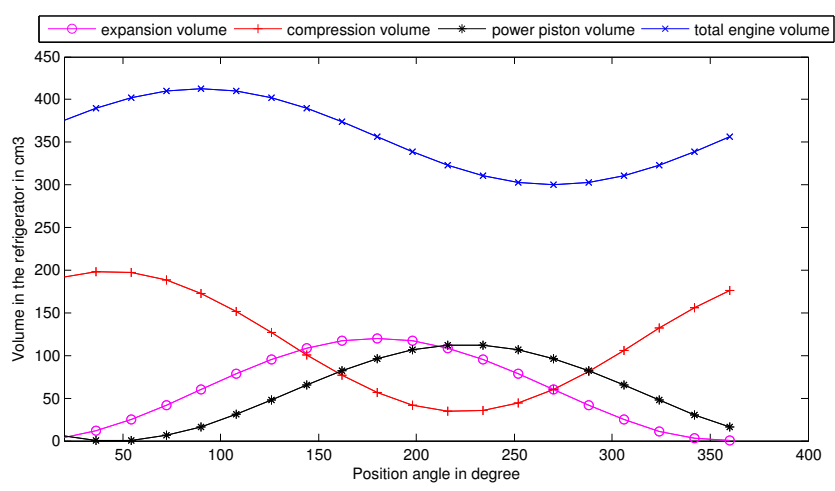

Fig. 7. Variation volume in the refrigerator-section

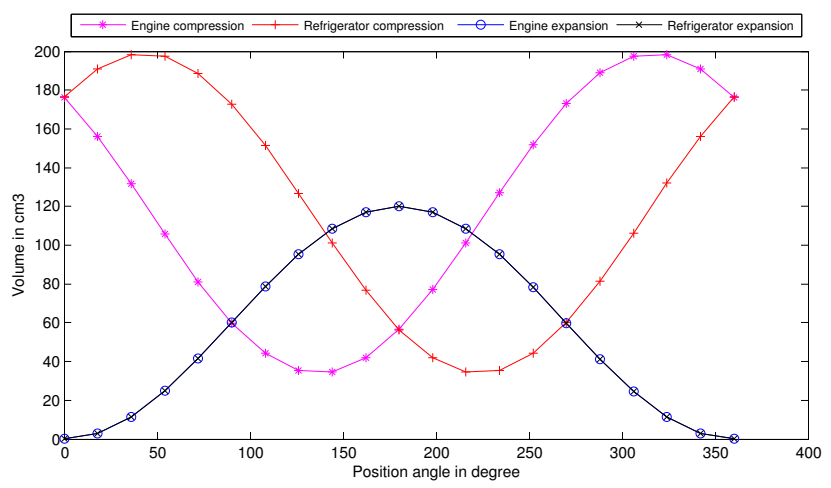

Fig. 8. Different working volume in the Duplex 


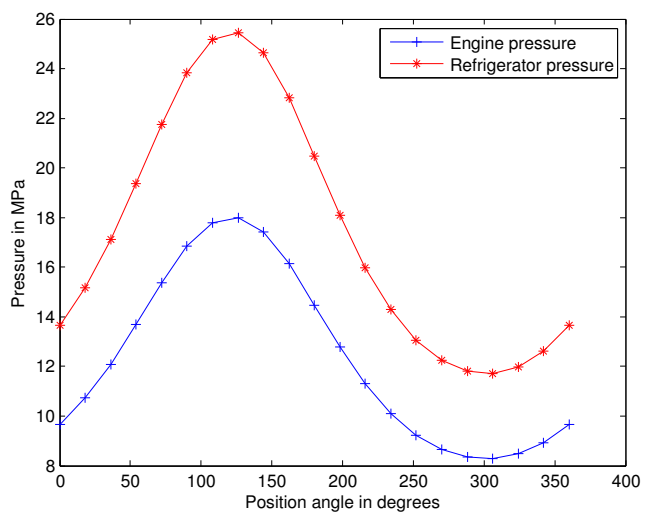

Fig. 9. Pressure variation in the Duplex

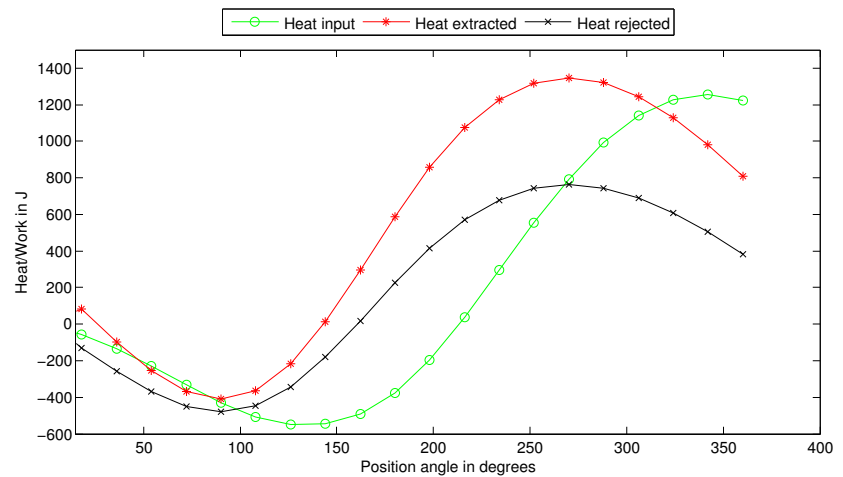

Fig. 10. Heat variation in the Duplex machine

\section{CONCLUSION}

In this study, several parameters of the Stirling Duplex machine are discussed. The working fluid considered is helium for its thermal characteristics (high heat transmission capacity) and chemical characteristics (stability) [13]. The adiabatic model used, based on the work of W. Martini [9] and L. Penswick [7], made it possible to highlight these studied parameters, such as the average pressures in the two sections of the machine, the different volumes depending on the position of the power piston, the temperatures the amounts of heat and work supplied and received, the coefficients of performance of the machine used as a refrigerating machine and as a heat pump.

\section{REFERENCES}

[1] G. Walker, R. Fauvel, S. Srinivasan, R. Gustafson, and J. Van Benthem, "Future coal-burning Stirling engines," Proceedings of the Institution of Mechanical Engineers, Part A: Power and Process Engineering, vol. 197, no. 1, pp. 37-44, 1983.

[2] C. J. Paul and A. Engeda, "A Stirling engine for use with lower quality fuels," Energy, vol. 84, pp. 152-160, May 2015. [Online]. Available: http://linkinghub.elsevier.com/retrieve/pii/S0360544215002935

[3] G. Walker, M. Weiss, R. Fauvel, and G. Reader, "Microcomputer simulation of Stirling cryocoolers," Cryogenics, vol. 29, no. 8, pp. 846849, 1989.
[4] H. Karabulut, H. Ycesu, and C. inar, "Nodal analysis of a Stirling engine with concentric piston and displacer," Renewable Energy, vol. 31, no. 13, pp. 2188-2197, Oct. 2006. [Online]. Available: http://linkinghub.elsevier.com/retrieve/pii/S0960148106000097

[5] D. Thombare and S. Verma, "Technological development in the Stirling cycle engines," Renewable and Sustainable Energy Reviews, vol. 12, no. 1, pp. 1-38, Jan. 2008. [Online]. Available: http://linkinghub.elsevier.com/retrieve/pii/S1364032106000906

[6] W. Beale and D. M. Berchowitz, Understanding Stirling engines. Volunteers in Technical Assistance, 1984.

[7] L. Penswick and I. Urieli, "Duplex-Stirling-Machines," California, Aug. 1984.

[8] G. Chen and W. Beale, "Thermally Actuated Duplex Free-Piston Stirling System for domestic, cooling and heating application," Beijing, China. [Online]. Available: https://sunpowerinc.com/wp-content/uploads/2014/08/Doc0048Thermally-Actuated-Duplex-Free-Piston-Stirling-System.pdf

[9] W. R. Martini, Stirling Engine Design Manual, university press of the pacific ed., 2004.

[10] J. Awrejcewicz, M. Kamierczak, J. Mrozowski, P. Olejnik, Politechnika dzka, Wydawnictwo, and Conference on Dynamical Systems - Theory and Applications, Eds., Dynamical systems: control and stability. d: Wydawnictwo Politechniki dzkiej, 2016, oCLC: 947203938.

[11] J. A. Araoz Ramos, Thermodynamic analysis of Stirling engine systems applications for combined heat and power. Stockholm: Industrial Engineering and Management, KTH Royal Institute of Technology, 2015, oCLC: 942094306. [Online]. Available: http://urn.kb.se/resolve?urn=urn:nbn:se:kth:diva-163048

[12] N. Kagawa, "An experimental study of a 3-kW Stirling engine," in Energy Conversion Engineering Conference and Exhibit, 2000.(IECEC) 35th Intersociety, vol. 1. IEEE, 2000, pp. 92-100.

[13] A. Asnaghi, S. M. Ladjevardi, P. Saleh Izadkhast, and A. H. Kashani, "Thermodynamics Performance Analysis of Solar Stirling Engines," ISRN Renewable Energy, vol. 2012, pp. 1-14, 2012. [Online]. Available: https://www.hindawi.com/archive/2012/321923/ 